\title{
Decision-Making for New Technology: A Multi-Actor, Multi-Objective Method
}

\author{
Scott W. Cunningham, Telli E. van der Lei \\ Delft University of Technology, Delft, Netherlands
}

\begin{abstract}
Technology managers increasingly face problems of group decision. The scale and complexity of research, development and alliance efforts in emerging fields of technology mandate a correspondingly sophisticated form of group coordination. Information technology, biotechnology and nanotechnology are good examples of sectors with complex coordination problems. Choices made include the selection of projects, the choice of investment alternatives, and the formation of technology licensing agreements. Multi-criteria decision analysis (MCDA) methods are often used to help decision makers in such situations.

A shortcoming of these methods is that the step from individual preferences to a collective preference is merely an aggregation. This aggregation of preferences requires the group of decision makers to agree on a collective preference. This paper presents a method that does not aggregate the individuals' preferences but instead considers strategic and economic factors in the assessment. We use an exchange coordination hypothesis, drawn from the theories of Coleman and other researchers, to support our model.

The advantage of this method is that the results provide an improved prescription for strategy, given the constraints of preferences and existing alliance structures. The model is motivated based upon the needs of technology managers in new, converging fields of technology. The model is formally analyzed using operations research techniques. We then apply the model to a representative technology management problem in the converging fields of informatics, bio and nanotechnology.
\end{abstract}

\section{INTRODUCTION}

Central to the modern conception of decision making is the concept of value. Values, as codified by von Neumann and others, specifically entail the idea of value at risk [1]. Thus concepts of decision making under risk, such as lotteries, are useful both for assess the value of a decision, and in assisting the analyst in prescribing an appropriate course of action [2]. Multi-criteria decision analysis uses the concept of value to prescribe desirable trade-offs between decision alternatives [3]. Game theory uses value to select an appropriate strategy faced with environmental or strategic uncertainty [4]. Thus two streams of decision making theory have arisen from the identical foundations of decisionmaking and value.

For both streams of decision making, value is exogenous to the model. Values are at the discretion of the decisionmaker, and are not affected by interactions with the social or economic environment. A more endogenous perspective on value creation is offered by cooperative game theory. In these models participants bargain or negotiate to create new sources of value $[5,6]$. However cooperative game theory suffers from a surplus of prescriptive recommendations.
There are multiple competing prescriptive recommendations for fairness in negotiation. Prescriptions for negotiated outcomes may vary widely according to the specifics of the case $[7,8]$.

The concept of revealed preferences is the leading method for operationalizing the concept of decision making value $[9,10]$. This entails measurement of actual decision making behavior and reverse inference about the nature of decision making values which are presumed to have guided the decision. Thus as analysts we infer the values of a decision-maker given evidence of prior decisions. Decision makers, however are constrained in their decision making capability - not just because of their values, but also because of the strategic context within which decisions are being made. Preferences, as revealed by the decisions of real actors are guided by values but are also strongly shaped by strategy.

The goal of this paper is to more thoroughly unify the literature on multi-criteria and multi-actor decision analyses. The results of this research may help to achieve a more design-oriented approach to guiding management of technology decisions in challenging areas of strategic decision making including alliance formation. The structure of the paper is as follows. Section II considers previous work in exchange modeling. Section III offers a brief survey of the literature on strategic alliances and technology management. The section further discusses the role of decision analysis in strategic and multi-criteria problem formulation. The section further presents a generic mathematical model of exchanges and alliances. Section IV provides a specific example of the decision model in the context of a corporate alliance problem. Section VIII concludes the paper with main conclusions and points for future research.

\section{PREVIOUS WORK}

In the following section we review literature concerned with prescriptive models for strategic decision making. Such models have been used in both the public and private sectors. Coleman pioneered work in modeling social exchange mechanisms $[11,12,13]$. Coleman postulated that actors exchanged control over issues to achieve desirable outcomes. This literature argues that deliberative processes in politics operate as a form of exchange. This is a valuable basis to begin consideration of similar models in the management of technology domain. The work has been critiqued by subsequent researchers $[14,15,16]$. Perhaps the most significant critique of the work is that actors have limited 
access to the halls of power. Thus the conditions for the free exchange of issues are not met in practice

Thus, the primary finding of research in this literature is that the configuration of actors strongly shapes the achievable outcomes of any group negotiation. The practical results of this work have informed the study of policy networks $[17,18,19,20]$. In the following paragraphs we further examine the management and strategy literature to better understand parallel development and application of models for decision-making under strategy.

Alliance activity between firms is on the rise. Research has focused on the diversity of alliance types with examples including $\mathrm{R} \& \mathrm{D}$ consortia, manufacturing and distribution alliances, and product bundling arrangements. Researchers have examined the locus of competition between firms, alliances, and even between competing constellations of alliances. A key motivator in the research has been a desire to explain differences in firm performance. The relational view of the firm, for instance, suggests that firm performance lies in the quantity and quality of network ties available to the firm. Alliance ties are seen as both conduits of information as well as sanctioning mechanisms.

An emerging literature on alliance formation focuses on the mechanisms firms use in achieving outcomes through the selection of appropriate business partnerships [21,22]. Thus this literature argues that firm objectives are a given, and are pursued through the decision variable of the appropriate selection of alliance partners. The decision is made more complex by the desire to have a range of different partners in terms of risk, compatibility, and intended duration of alliances. This decision problem is the converse to the political exchange problem where exchange structure is taken as a given, and the revealed preferences are therefore an emergent phenomenon governed by the aggregation of group preferences.

The optimal design of alliance strategies has been a topic of debate. One literature argues that dense networks of strong, closed ties are maximally advantageous to the firm. This literature argues that such networks promote consensus, shared values, and reduce coordination and transaction costs. An alternative perspective emphasizes the role of loose, distant, and diverse ties. Alliances which bridge structural holes, and thus generate new knowledge and innovative ideas, are to be particularly valued from this perspective $[23,24]$.

Alliances are subject to a dilemma of incomplete, and often unenforceable contracting, Alliance activity is thus governed by the risks of moral hazard and of free riding. Firms therefore carefully screen partners using a variety of mechanisms, including third party endorsement. A strategic perspective on risky alliance activity emphasizes the significance of repeated games given the threat of contingent selection. Network ties become a means for reducing opportunistic behaviors and reducing monitoring costs $[25,26,27,28,29]$.

The literature demonstrates the significance of alliance activity for high technology companies. The significance of alliance activity in a variety of industries including semiconductors, telecommunications and biotechnology is addressed $[30,31,32,33]$. More broadly, the issue has been characterized as a challenge of managing value creation with networks under distributed and decentralized control [34,35].

In the following section we compare and contrast four models of decision-making, resulting in a progressively more complex depiction of group decision-making. The typical engagement structure and goals of each of the models are further detailed. We create our own systems model of strategic decision-making in order to better compare the assumptions and advisory practice behind these four kinds of decision models.

\section{BASIC ELEMENTS OF THE MODEL}

The model of multi-criteria decision analysis contains a single actor, making a decision against nature. The resultant delivery of desired outcomes is subject to risk from nature. Many multi-criteria decision analysis (MCDA) techniques structure the decision-making process by introducing a value function which prescribes desirable trade-offs between all achievable outcomes. Outcomes may have multiple attributes which may be used in their assessment through the value function. A weight on different outcomes or attributes is used to consider a range of rational preferences intrinsic to the decision-maker (figure 1).

The role of the decision-analyst in a multi-criteria analysis is to assist the decision-maker in clarifying the nature of the risks, outcomes, and value functions at stake in a given decision. A structured interview or engagement is used to determine the correct decision weights needed to best reflect the preferences of a given decision-maker [36].

One basic group MCDA technique makes only a minor modification to this basic scheme. A group of stakeholders, who are party to a decision, are consulted to determine their decision preferences. Both a weighting scheme for individual decision-makers is used, as well as an aggregating scheme to translate individual preferences into a recommendation for group action. The technique is problematic for several reasons not the least of which is the interpersonal comparison of utility. Furthermore the expression of weights is subject to political gaming as participants seek to drive the process to personally preferred outcomes [37]. For these reasons, as well as others, a measure of decision consensus may be introduced by a facilitator. The group is thereby encouraged to identify, and resolve, differences of opinion [38]. 


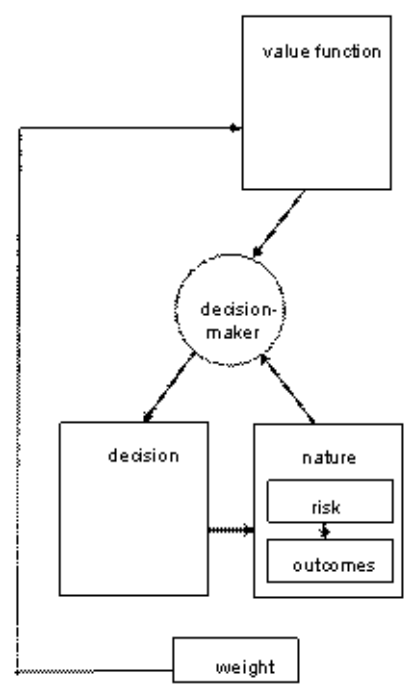

MCDA

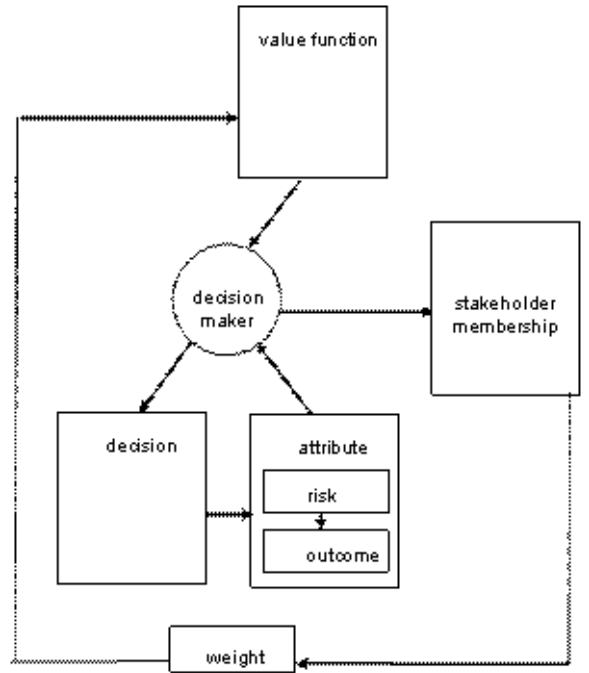

Group MCDA

Fig. 1.Model Elements for MCDA and Group MCDA.

An alternative account of group-decision processes is offered by the group exchange literature. This literature, inspired by computational models of the marketplace [39], suggests that even non-economic forms of decision-making may be described and governed by an exchange mechanism. Some additional elements to the model are required in order to embrace this exchange mechanism (figure 2).

In the exchange model decisions are made not against nature, but against self-interested players. A predetermined market structure dictates who may trade which outcomes. Individual decision weights are supplanted by the going market exchange rate. As a result individuals with more say over outcomes of interest to the group have greater control over the decision-making process. Some minor chang es in model terminology are required consistent with the exchange literature. Decision and nature become "control." The value function becomes "interest." Decision weights become the "exchange rate." Stakeholder members are governed by an "exchange structure" which regulates the nature of group decision-making (figure 2).

Analysts operating with this model must identify stakeholders, exchange structures, as well as outcomes and issues for a given case. Each stakeholder possesses a degree of control and interest over outcomes. The exchange rate between issues emerges from the model. The model may be used in engagement to assist group decision-making by helping group members identify issues of interest, recognize points of compromise, and to drive outcomes to maximally satisfactory conclusions. Examples of decision-aiding by means of the exchange model include public sector example of land use negotiation [40], as well as a private sector example involving the financial restructuring of a large farm cooperative [17].

The exchange model has been critiqued on a number of factors. Limited participant access may certainly change the equilibrium outcome, as well as resultant prescriptions for action. Well-connected exchange members have a better bargaining position by falling back to "outside options" whenever necessary. This structural critique may be relatively limited since a more networked exchange may be readily incorporated into the basic model, as for instance, as incorporated into the works of Marsden $[14,15]$. We will further consider the validity of these networked extensions to the exchange model in the conclusions of the paper.

Another critique concerns the completeness of the representation of actors used in exchange models. Actor interests may be more complexly defined by considering both their range of desired outcomes ("consumption"), as well as their transformative capacity for action ("production"). Actors also may strongly differ in their base endowment of decision-relevant "goods." In many regards the sociological exchange model abstracts some facets of economic life that may be usefully restored when modeling problems in the management of te chnology domain.

A still more serious basis for critique of exchange models is the idea that the fundamental exchange of control between actors entails a measure of risk. The management of risk and incentives between parties with incomplete or assymmetric information constitutes a significant body of ongoing research [41]. In this regard, the multi-criteria model provides a richer account of single-actor decision-making under risk than available in the conventional exchange model.

Furthermore this risk may be mitigated by the exchange structure itself. Third-party recommendations between actors, and contingent renewal of agreements between actors, assist in sanctioning unreliable exchange behavior. A final enrichment to the model (figure 2) comes from the literature on strategic alliances. This literature examines the way in which alliance struetures change over time, advantaging certain participants at the expense of others. This model includes insights from both economic exchange models as well as strategic models of alliance formation. 


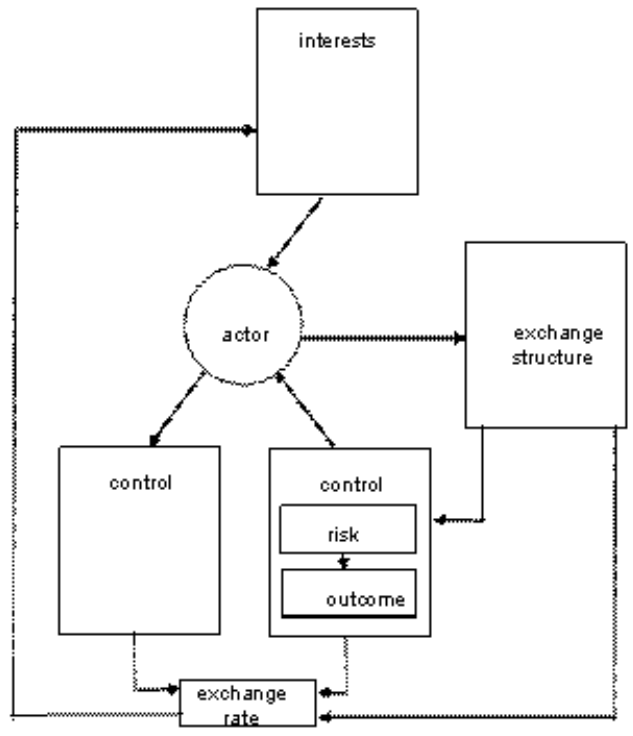

Exchange Model

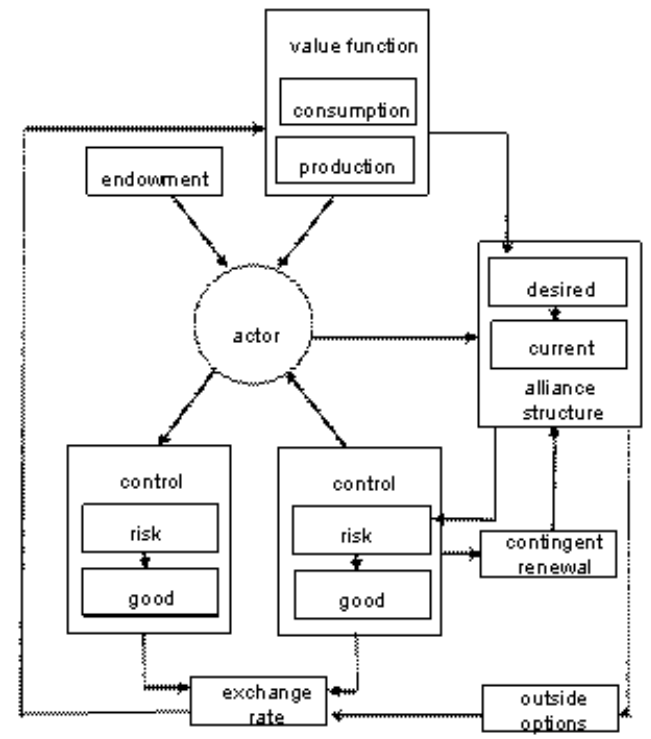

Alliance Model

Fig.2. Basic model components in the ex change and alliances model.

Analytical engagement using alliance models may take several forms. Modeling efforts may be intended as a theoretical explanation of real-world processes. The parameterization of the model to support decision-making may therefore not be of primary concern. Alliance models may also be used for making policy recommendations. After fully specifying the model, an analyst may run a range of different policy experiments to determine likely changes in system structure and outcome. Work of this character historically has been done questions of a more economic than strategic character [39]. Policy experiments on alliance structures, on the other hand, remains a relativ ely new field of investigation.

Analytical work of this character no longer presumes unitary action (as for instance in much of the group MCDA literature). The analyst therefore forms prescriptions for action for a single actor, while taking into account a range of likely strategic behavior by other participants in the system. Value preferences for other actors in the system is not known, but is often imputed using techniques such as revealed preference.

\section{MODEL ANALYSIS AND APPLICATION}

The fundaments of the model are discussed in Appendix A. At this point it is most important to note from this derivation that actor interests, actor control, and the network structures permitted establish the going rate of exchange for goods within the system. In this section we will provide a hypothetical example of the transactional approach for alliance formation in the microelectronics industry.

The case is inspired by a newsworthy supply chain failure [42]. The supply chain in question included notable participants such as Sony, Ericsson and Nokia. The goal of the case is to demonstrate the mathematical modeling discussed in the previous section, as well as to provide a realistic motivating case for discussion. However it is not the purpose of the case to provide specific strategic advice to the companies involved, and therefore we do not seek a careful parameterization of the network and utility structure of the participants involved.

Nonetheless, we offer for illustration purposes a list of possible particip ants in a microelectronics alliance:

TABLE I

EXCHANGE PARTICIP ANTS

\begin{tabular}{|ccc|}
\hline Alcatel-Lucent & Motorola & Sagem Communication \\
Ericsson & Nokia Corporation & Sam sung \\
Matsushita Electric Industrial & Nortel Networks & Siemens \\
Micron Technology & Royal Philips Electronics & Sony \\
\hline
\end{tabular}


Figure 3 shows a hypothetical fully connected exchange between these twelve microelectronics suppliers and manufacturers.

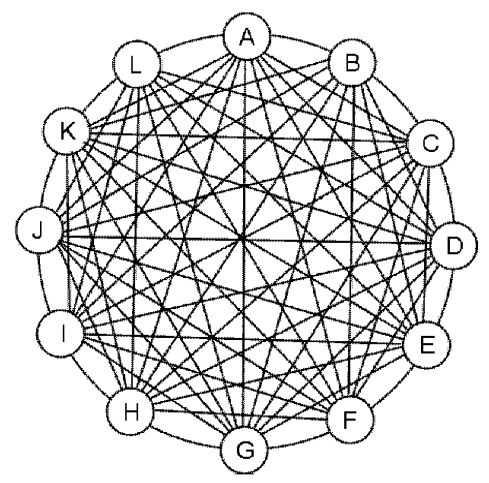

Fig.3. Full Exchange Structure.

Together the alliance participants are trading a number of different kinds of technical and business expertise for mutual benefit, including wireless technology, microelectronics manufacturing, and global marketing capability. Each alliance participant has its own native capability (control), as well as its own distinct desired outcomes (interests).

We might take for example alliance partner $\mathrm{A}$, which has control over $10.4 \%$ of the total market capability in developing new wireless technology. They are significantly less capable in microelectronics manufacturing and marketing (less than $1 \%$ of the total in each). Their strategic goals are to capitalize on their wireless technology, and to expand their microelectronic manufacturing base. Direct marketing to consumers is not a priority. A corresponding specification of interests for this company might therfore be the following: ( $72 \%$ wireless / $26 \%$ microelectronics / $2 \%$ marketing).

In the Coleman model exchange participants are able to freely exchange goods to achieve their desired outcomes. Decision-makers are subject to budgetary constraints, which are determined by the market valuation of the goods under their control. The calculations for this are described in Appendix A. A market price for each commodity can be determined (table 1). Then the equilibrium resource levels for each company can be determined (Table II).

TABLE II

EQUILIBRIUM EXCHANGE RATES FOR GOODS

\begin{tabular}{lr|} 
& $\begin{array}{r}\text { Exchange } \\
\text { Rate }\end{array}$ \\
\cline { 2 - 2 } Wireless Technology & 0.308 \\
\cline { 2 - 2 } Microelectronic & \\
Manufacturing & \\
Global Marketing & 0.394 \\
Capability & 0.298 \\
\cline { 2 - 2 } &
\end{tabular}

TABLE III

EQUILIBRIUM RESOURCE LEVELS AFTER EXCHANGE (MATRIX R).

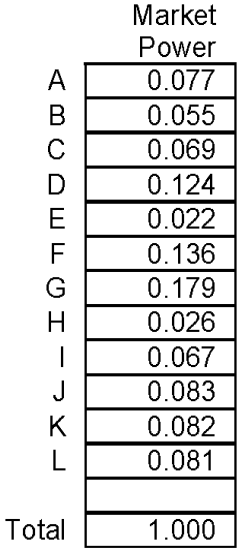

In this specific example the market places a high premium on microelectronic manufacturing skills. Our representative company, company A, is highly capable in wireless technology but like many other companies in this hypothetical exchange members all place a high demand for microelectronic capabilities. As a result it fares comparatively poorly in the marketplace, receiving little of the good it needs to achieve its own strategic objectives.

Note that in this example all quantities (control, interest, resource levels, and prices) are unit-less. The specific units and quantities are determined by the problem involved. We may drop units from the analysis without any loss of generality. We may also select our units for prices and resource levels - the numeraire -- as we wish. What is fundamental to the problem is the ratio of the price of goods and services, not the specific units of measurement [39].

We now expand the exchange model still further by hypothesizing a specific alliance structure which guides the permissible trades between participants. Limited access between participants is the norm is such alliance activities, thus a networked model produces a greater fidelity of results to actual strategic behaviors.

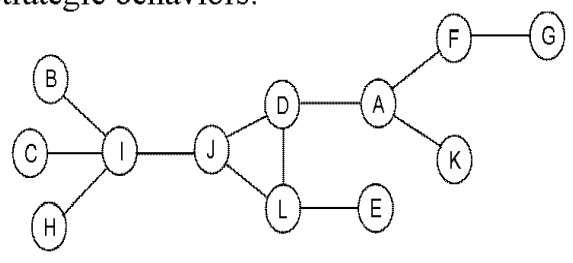

Fig.4. Network Structure.

In general we would expect group outcomes to be lower (as free and open trading is no longer possible, and viable trades between participants are lost). However some network participants, such as the centrally located companies J, D, and $\mathrm{L}$ may preferentially benefit from the exchange. As will be seen below, it is the specific configuration of actors and interests that dictates the network outcomes. 
TABLE IV

EQUILIBRIUM EXCHANGE RATES FOR GOODS UNDER NETWORKED COORDINATION

\begin{tabular}{|r|}
$\begin{array}{c}\text { Exchange } \\
\text { Rate }\end{array}$ \\
\hline 0.347 \\
\hline 0.403 \\
\hline \\
0.250 \\
\hline
\end{tabular}

In this example alliance, the configuration places a further demand on microelectronic manufacturing, and wireless technology, already the scarce resources in the system. In contrast the exchange rate for global marketing is further depressed. The networked exchange process further advantages certain actors compared with the free trade model of exchange (Table $\mathrm{V}$, below).

As can be seen our exemplar company, company A, is further disadvantaged by its position in the alliance constellation. Increasingly limited access to desired microelectronic skills further reduces the competitiveness of this company. In this specific example, most companies were advantaged by the network constellation and only three were made comparatively worse off (companies A, G, L).

TABLE V

EQUILIBRIUM RESOURCE LEVELS AFTER NETWORKED EXCHANGE (MATRIX R)

\begin{tabular}{|c|c|c|}
\hline & $\begin{array}{r}\text { Free } \\
\text { hange }\end{array}$ & $\begin{array}{l}\text { Networked } \\
\text { Exchange }\end{array}$ \\
\hline A & 0.077 & 0.040 \\
\hline B & 0.055 & 0.086 \\
\hline C & 0.069 & 0.090 \\
\hline D & 0.124 & 0.096 \\
\hline$E$ & 0.022 & 0.084 \\
\hline $\mathrm{F}$ & 0.136 & 0.116 \\
\hline G & 0.179 & 0.039 \\
\hline $\mathrm{H}$ & 0.026 & 0.108 \\
\hline I & 0.067 & 0.148 \\
\hline $\mathrm{J}$ & 0.083 & 0.120 \\
\hline $\mathrm{K}$ & 0.082 & 0.032 \\
\hline L & 0.081 & 0.041 \\
\hline & 1.000 & 1.000 \\
\hline
\end{tabular}

In our last set of numerical experiments we calculate the potential economic advantage or disadvantage of adding or subtracting alliance links in the network. We perform these experiments using company $\mathrm{A}$ as an example.
TABLE VI

VALUE AND MARGINAL VALUE OF ALLIANCE PARTNERSHIPS

\begin{tabular}{|c|c|c|c|}
\hline & $\begin{array}{l}\text { Change in } \\
\text { Alliance } \\
\text { Structure }\end{array}$ & $\begin{array}{l}\text { Equilibrium } \\
\text { Resources }\end{array}$ & $\begin{array}{l}\text { Marginal } \\
\text { Value of } \\
\text { Change }\end{array}$ \\
\hline A & baseline & 0.0400 & 0.0000 \\
\hline B & add & 0.0394 & -0.0006 \\
\hline C & add & 0.0397 & -0.0003 \\
\hline D & remove & 0.0396 & -0.0004 \\
\hline$E$ & add & 0.0392 & -0.0008 \\
\hline $\mathrm{F}$ & remove & 0.0396 & -0.0004 \\
\hline G & add & 0.0396 & -0.0004 \\
\hline $\mathrm{H}$ & add & 0.0393 & -0.0007 \\
\hline I & add & 0.0395 & -0.0005 \\
\hline $\mathrm{J}$ & add & 0.0393 & -0.0007 \\
\hline $\mathrm{K}$ & remove & 0.0401 & 0.0001 \\
\hline L & add & 0.0398 & -0.0002 \\
\hline
\end{tabular}

Company $\mathrm{A}$ is in the position of both being disadvantaged by its network position, and also having very little strategic recourse to bilaterally improve its position. Most single link additions or subtractions to the alliance structure deplete the equilibrium resources of the company. Removing one link however, the link to company $\mathrm{K}$, increases the equilibrium resource levels of the company. It is possible that dropping this alliance enables the company to redouble its efforts with the other more profitable alliances in its portfolio.

We conclude with some comments on the character of advice provided by the exchange model. Results from the exchange model are markedly different from multi-criteria decision analysis. Certainly the standard multi-criteria model may be useful in this setting by assisting decision makers to set their strategic interests for the company. However the emergent weighting of key goods in this industry is determined in significant part by the alliance structure of the model, and the collective and strategic action of other players. Likewise the assessment of marginal value of alliance partnerships is determined in large part by the embedded nature of the firm within this alliance constellation. Given the strategic character of action in the sector, a single group decision model, where pooled evaluations of necessary new industrial enhancements are made, may not be feasible.

\section{CONCLUSIONS AND FUTURE RESEARCH}

The previous sections provided mathematical details of an exchange model, as well as a simple numerical example illustrating a microelectronics supply chain. Existing results from models of political activity are extended to a problem of management of technology. The model is also used to demonstrate new results, in the form of sample strategic advice on alliance formation. In particular, the paper examined the consequences of restricted access to network resources in determining desired outcomes for a firm in an alliance formation situation. The model, if parameterized to a specific problem setting, may be used to evaluate existing 
alliance networks, design new networks, and select new alliance partners. Parallel efforts in the field of network games are describing the underlying logic of strategic action in networks, and thereby providing new insight into the growth and formation of business and technology networks [43].

This paper has pursued a tighter integration between models of multi-criteria analysis and multi-actor modeling. The paper created an exchange model of decision-making, and related the resultant group valuation of outcomes to a broad class of multi-criteria decision making problems. The nature of policy advice across four different models of decision-making is then considered in some detail. The resultant combination of modeling approaches offered new insights, extensions, and critiques to the field of group decision-making.

New and converging technologies constitute an important and interesting area of research for management of technology. The case discussed in the article is motivated by a problem of alliances in the information technology sector. The significance and complexity of alliance formation in these industries is a topic of ongoing research. Evidence suggests that it is a hallmark of technology development in these new and emerging industries. Management of converging technologies therefore require special care in the valuation of strategies, partners, and the decentralized management of value $[30,31,32,33,34]$. The results of this paper may assist in part in the ongoing research into new approaches for managing these technologies.

Perhaps the most pressing concern in further expanding and exploring the model lies in the assumptions of price equilibrium in a network. The networked extensions to the exchange model, as proposed by Marsden, argue that a networked alliance should be able to converge to a single, globally applicable exchange rate for goods and services on the network. Recent research suggests that these unitary valuations, in absence of external institutions such as government regulation, will not hold at equilibrium [44].

Individual companies can and will profit by raising prices locally on the network. The dual to this problem of local pricing is the alliance allocation decision: given scarce resources, where must alliance trades be made to maximally enhance profitability? Prior results in the field of cooperative games suggest that an equilibrium coalition structure requires maintaining a balanced investment by all alliance partners, where certain alliances are more likely to be favored partnerships [8]. Other results on network equilibrium re being generated within the field of network games, as well as within the transportation policy literature in the context of multi-commodity flows [45].

Coleman initiated efforts to research the role of trust within exchange networks. More recent efforts have examined the role of iterated games played on a network, such as the game "iterated prisoner's dilemma with choice and refusal." Information economics, and especially contract theory, are investigating the nature of strategic relationships when there is asymmetric information, such as about the reliability of a partner [41]. This area is also a fruitful for future investigation.

\section{ACKNOWLEDGEMENT}

The authors appreciate useful feedback from their colleagues Leon Hermans, Jan Kwakkel and Erik Pruyt.

\section{REFERENCES}

[1] Von Neuman, J., O. Morgenstern, The Theory of Games and Economic Behavior, John Wiley \& Sons, 1944.

[2] French, S., Decision Theory, Ellis Horwood, 1989.

[3] Keeney, R. L., H. Raiffa, Decisions with Multiple Objectives: Preferences and Value

Tradeoffs, Cambridge, 1993.

[4] Luce, R. D., H. Raiffa, Games and Decisions: Introduction and Critical Survey, Dover Publications, 1957.

[5] Nash, J. F., "The Bargaining Problem," Econometrica, vol.18, pp.155162,1950 .

[6] Nash, J. F., "Two-person Cooperative Games," Econometrica, vol.21, pp.128-140, 1949.

[7] Kahan, J. P., A. Rapoport, Theories of Coalition Formation, Lawrence Erlbaum, 1984.

[8] Osborne, M. J., A. Rubinstein, A Course in Game Theory, MIT Press, 1994.

[9] Samuelson, P. A., "A Note on the Pure Theory of Consumer's Behavior," Econometrica, vol.5, no.7.pp.61-71, 1938 .

[10] Varian, H., "Revealed Preference," in Szenberg, M., Samuelsonian Economics and the $21^{\text {st }}$ Century, Oxford University Press, 2005.

[11] Coleman, J. S., "Systems of Social Exchange," Journal of Mathematical Sociology, vol. 2, pp. 145-163, 1972.

[12] Coleman, J. S., The Mathematics of Collective Action, Aldine, 1973.

[13] Coleman, J. S., Foundations of Social Theory, Harvard University Press, 1990.

[14] Marsden, P. V., "Models and methods for characterizing the structural parameters of groups," Social Networks, vol.3, pp.1-27, 1981.

[15] Marsden, P. V., "Restricted Access in Networks and Models of Power," American Journal of Sociology, Vol.88, pp.686-717, 1983.

[16] Stokman, F. N., J. M. M. van den Bos, "A Two-Stage Model of Policy Making with an Empirical Test in the U.S. Energy Policy Domain, pp.219-253, in G. Moore and J. A. Whitt (eds.), The Political Consequences of Social Networks, JAI Press, 1992.

[17] Stokman, F. N., E. P. H. Zeggelink, "Is Politics Power or Policy Oriented? A Comparative Analysis of Dynamic Access Models in Policy Networks," Journal of Mathematical Sociology, Vol.2, No.1-2, pp.77-111, 1996.

[18] Knoke, D., "Networks of Elite Structure and Decision Making," Sociological Methods \& Research, vol.22, pp.23-45, 1992.

[19] Sharpf, F., Games Real Actors Play: Actor-Centered Institutionalism in Policy Research, Westview Press, 1997.

[20] Koppenjan, J., E. H. Klijn, Managing Uncertainties in Networks: A Network Approach to Problem Solving and Decision Making, Routledge, 2004

[21] Gulatti, R., "Alliances and Networks," Strategic Management Journal, Vol.19, pp.293-317, 1998.

[22] Gulatti, R. "Network Location and Learning: The Influence of Network Resources and Firm Capabilities on Alliance Formation," Strategic Management Journal, Vol.20, pp.397-420, 1999.

[23] Zaheer, A., G. G. Bell, "Benefiting from Network Position: Firm Capabilities, Structure Holes, and Performance," Strategic Management Journal, Vol.26, pp.806-825, 2005.

[24] Oh, H., Labianca, G., M.-H. Chung, "A Multilevel Model of Group Social Capital," Academy of Management Review, Vol.31, No.3, pp.569-582, 2006. 
[25] Doz, Y. L., P. M. Olk, P. S. Ring (2000), "Formation Processes of R\&D Consortia: Which Path to Take? Where Does it Lead?," Strategic Management Joumal, Vol.21, pp.239-266, 2000.

[26] Gintis, H., Game Theory Evolving: A Problem-Centered Introduction to Modeling Strategic Behavior, Princeton University Press, 2000.

[27] Arend, R. J., D. A. Seale, "Modeling Alliance Activity: An Iterated Prisoners' Dilemma with Exit Option," Strategic Management Joumal, Vol.26, No.1057-1074, 2005.

[28] Tirole, J., The Theory of Industrial Organization, MIT Press, 2002.

[29] Das, T.K., B.-S. Teng, "Alliance Constellations: A Social Exchange Perspective," Academy of Management Review, Vol.27, No.3, pp.445$456,2002$.

[30] Stuart, T. E., "Interorganizational Alliances and the Performance of Firms: A Study of Growth and Innovation Rates in a High-Technology Industry," Strategic Management Joumal, Vol.28, No.8, pp.791-811, 2000.

[31] Baum,. J. A. C., T. Calabrese, T., B. S. Silverman, "Don't Go It Alone: Alliance Network Composition and Startups' Performance in Canadian Biotechnology," Strategic Management Joumal, Special Issue, Vol.21, No.3, pp.267-294, 2000.

[32] Lee, G. K., "The Significance of Network Resources in the Race to Enter Emerging Product Markets: The Convergence of Telephony Communications and Computer Networking, 1989-2001," Strategic Management Journal, Vol.28, pp.17-37, 2007.

[33] Maurer, I., M. Ebers, "Dynamics of Social Capital and Their Performance Implications: Lessons from Biotechnology Start-Ups," Administrative Science Quarterly, Vol.51, pp.262-292, 2006.

[34] Schneeweiss, C., K. Zimmer, "Hierarchical Coordination Mechanisms within the Supply Chain," European Joumal of Operational Research, Vol.153, No.3, pp.687-703, 2004

\section{APPENDIX A. MATHEMATICAL DERIVATIONS}

The following derivations are due to Coleman [11][12][13]. A collection of $\mathrm{n}$ actors exercise control over $\mathrm{m}$ goods. This is expressed in a $\mathrm{C}$ matrix dimensioned $\mathrm{n}$ by $\mathrm{m}$. Control by a given actor is normalized to 1.00 without loss of generality. Similarly, actors have interest in a set of goods which may not be the same goods over which they have control. This matrix is represented by $\mathrm{X}$, and for convenience is transposed and therefore dimensioned $m$ by $n$. We may also scale these matrices without loss of generality so that the sum total of control across each actor sums to 1.00 , and the sum of control of interest across each good also sums to 1.00 .

The utility of each actor for receiving control over goods is expressed in the following equation, where utility is an $n$ by 1 matrix. Equivalently we may take the $\log$ of utility (call this W). This simplifies calculations, and since $W$ is a monotonic function of $\mathrm{U}$, there is no loss of generality. (See equations $1 \mathrm{a}$ and $1 \mathrm{~b}$, below).

$$
\begin{array}{ll}
\text { Eq. 1a } & U=\prod_{i=1}^{m} c_{i}^{\times i} \\
\text { Eq. 1b } & W=\ln (U)=\sum_{i=1}^{m} X \ln (\mathrm{C})
\end{array}
$$

We hypothesize a final set of market values, determining the final exchange valuation of each good. This matrix, $\mathrm{V}$ is a $\mathrm{m}$ by 1 matrix. Actors have resources $\mathrm{R}$ which are proportional to the final valuation of their goods times their control. follows:
[35] Schneeweiss, C., K. Zimmer, M. Zimmermann, "The Design of Contracts to Coordination Operational Interdependencies within the Supply Chain," International Joumal of Production Economics, Vol.92, No.1, pp.43-59, 2004.

[36] Belton, V., T. J. Stewart, Multiple Criteria Decision Analysis: An Integrated Approach, Kluwer Academic Press, 2002.

[37] Arrow, K. J., Social Choice and Individual Values, Wiley, 1951.

[38] Bots, P. W. G., J. A. M. Hulshof, "Designing Multi-Criteria Decision Analysis Processes for Priority Setting in Health Policy," Journal of Multi-Criteria Decision Analysis, Vol.9, No.1-3, pp.56-75, 2000.

[39] Shoven, J. B., J. Whalley, Applying General Equilibrium, Cambridge University Press, 1992.

[40] Timmermans, J., Purposive Interaction in Multi-Actor Decision Making: Operationalizing Coleman's Linear System of Action for Policy Decision Support, Eburon, 2004.

[41] Laffont, J.-J., D. Martimont, The Theory of Incentives: The PrincipalAgent Model, Princeton University Press, 2002.

[42] Lynn, B., End of the Line: The Rise and Coming Fall of the Global Corporation, Currency, 2006.

[43] Jackson, M. O., "A Survey of Models of Network Formation: Stability and Efficiency," in Demange, G., M. Wooders, eds. Group Formation in Economics, Cambridge University Press, 2005.

[44] Kakade, S. M., M. Kearns, L. E. Ortiz, "Graphical Economics," in Shawe-Taylor, J., Y. Singer, eds. Proceedings of the Conference on Learning Theory, 2004.

[45] Bouhtou M., M. Diallo, L. Wynter, "Capacitated Network Revenu Management Through Shadow Pricing," Proceedings Lecture Notes in Computer Science, vol.2816, pp.341-353,2003.

[46] Langville and Meyer, "Deeper Inside Page Rank," Internet Mathematics, Vol.1, No.3, pp.335-380, 2004.

$$
\text { Eq. } 2 \begin{aligned}
& \text { maximize }(W) \text {, } \\
& \text { with respect to } C \\
& \text { subject to } R=C V
\end{aligned}
$$

All actors in the system maximize their utility with respect to their decision to exchange control with other actors. However they are subject to a budget, as they are limited to a sum total of exchanges which are equal to their resources.

The problem may be solved using a Lagrangian, as shown below in equations $3 a-3 c$. The problem reduces to $m$ equations (one for each actor), plus an additional equation to calculate the Lagrangian multiplier (equation $3 \mathrm{c}$ ).

$$
\begin{array}{ll}
\text { Eq. 3a } & \mathscr{L}=W+\lambda(R-C V) \\
\text { Eq. 3b } & \frac{\mathrm{d} \mathscr{L}=X-\lambda V}{\mathrm{dC}} \\
\text { Eq. 3c } & \frac{\mathrm{d} \mathscr{L}=\mathrm{R}-\mathrm{CV}}{\mathrm{dC}}
\end{array}
$$

Additional linear algebra calculation allows further derivation of the following equations. Equation 4a shows how the stationary value of $\mathrm{R}$ is a function of actor control and interest. Marsden further elaborated the model to include network constraints of trade, where the matrix $A$ is a $n$ by $n$ matrix indicating the social structure of the exchange network. Trades permitted by the network structure of the model are indicated by a 1 in the matrix; trades not permitted by network structure are indicated by a 0 . This model too has a potential Markov chain solution (equation $4 \mathrm{c}$ ).

$\begin{array}{ll}\text { Eq. } 4 \mathbf{a} & \mathrm{R}=\mathrm{RXC} \\ \text { Eq. } 4 \mathbf{b} & \mathrm{R}=\mathrm{RA} \\ \text { Eq. } 4 \mathrm{c} & \mathrm{R}=\text { RAXC }\end{array}$


Also determined by these equations is the exchange rate (V) for goods in the political or economic exchange. This is the dual problem to determining individual actor resources. As noted earlier this exchange rate is significant across a number of models of group decision analysis. Appendix B provides additional mathematical detail about the solution of these equations (4a-4c).

As a side note it is interesting to note that web search engines calculate the significance of any given page in terms of its "exchange" of hyperlinks with other significant pages on the internet. This model, embodied in the Google search engine, is fundamentally similar to the Coleman and Marsden models [46].

\section{APPENDIX B. WORKED EXAMPLE}

Table I (below) shows a hypothetical control matrix for twelve microelectronics firms. This corresponds to the $\mathrm{C}$ matrix in standard exchange models. Quantities in the table are normalized by column, so that for instance the sum total of "wireless expertise" is summed to $100 \%$. Quantities in this table might be estimated by research and development indicators (such as patenting).

TABLE I

CONTROL MATRIX (MATRIX C)

\begin{tabular}{|c|c|c|c|}
\hline \multirow{3}{*}{$\begin{array}{l}A \\
B\end{array}$} & Wireless & Micro-Electronics & Marketing \\
\hline & 0.104 & 0.005 & 0.007 \\
\hline & 0.000 & 0.071 & 0.229 \\
\hline $\mathrm{C}$ & 0.015 & 0.196 & 0.025 \\
\hline D & 0.160 & 0.095 & 0.008 \\
\hline$E$ & 0.008 & 0.092 & 0.177 \\
\hline $\mathrm{F}$ & 0.167 & 0.137 & 0.011 \\
\hline G & 0.070 & 0.000 & 0.057 \\
\hline $\mathrm{H}$ & 0.186 & 0.000 & 0.174 \\
\hline I & 0.136 & 0.248 & 0.004 \\
\hline $\mathrm{J}$ & 0.119 & 0.155 & 0.064 \\
\hline $\mathrm{K}$ & 0.023 & 0.001 & 0.095 \\
\hline L & 0.012 & 0.000 & 0.148 \\
\hline Total & $100 \%$ & $100 \%$ & $100 \%$ \\
\hline
\end{tabular}

Table II (below) shows a hypothetical interest matrix for twelve microelectronics firms. This corresponds to the $\mathrm{X}$ matrix in standard exchange models. Note that the table, as shown, is transposed. Quantities in the table are normalized by row, so that for instance the sum total of interest of alliance partner "A" is summed to $100 \%$. Quantities in this table might be estimated through interviews, yearly reports, or industrial classification schemes. A traditional multicriteria decision analysis approach might also be incorporated here.

TABLE II

\begin{tabular}{|c|c|c|c|c|}
\hline \multicolumn{5}{|c|}{ INTEREST MATRIX (MATRIX X, TRANSPOSED) } \\
\hline & wireless & micro-electronics & marketing & Total \\
\hline A & 0.720 & 0.264 & 0.016 & 1.000 \\
\hline B & 0.227 & 0.036 & 0.736 & 1.000 \\
\hline C & 0.558 & 0.294 & 0.148 & 1.000 \\
\hline D & 0.526 & 0.421 & 0.053 & 1.000 \\
\hline $\mathrm{E}$ & 0.000 & 0.273 & 0.727 & 1.000 \\
\hline $\mathrm{F}$ & 0.578 & 0.266 & 0.156 & 1.000 \\
\hline G & 0.492 & 0.246 & 0.262 & 1.000 \\
\hline $\mathrm{H}$ & 0.000 & 0.885 & 0.115 & 1.000 \\
\hline & 0.292 & 0.053 & 0.655 & 1.000 \\
\hline J & 0.018 & 0.950 & 0.032 & 1.000 \\
\hline K & 0.188 & 0.635 & 0.177 & 1.000 \\
\hline 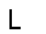 & 0.665 & 0.332 & 0.003 & 1.000 \\
\hline
\end{tabular}

The example in section 4 was run both with complete access to partners, and with limited access to partners. Table 4 (below) shows a hypothetical alliance structure for this analysis.

TABLE III ALLIANCE STRUCTURE

\begin{tabular}{|c|c|c|c|c|c|c|c|c|c|c|c|c|}
\hline & A & B & C & D & $E$ & $F$ & G & H & 1 & $\mathrm{~J}$ & K & L \\
\hline A & 1 & 0 & 0 & 1 & 0 & 1 & 0 & 0 & 0 & 0 & 1 & 0 \\
\hline$B$ & 0 & 1 & 0 & 0 & 0 & 0 & 0 & 0 & 1 & 0 & 0 & 0 \\
\hline & 0 & 0 & 1 & 0 & 0 & 0 & 0 & 0 & 1 & 0 & 0 & 0 \\
\hline & 1 & 0 & 0 & 1 & 0 & 0 & 0 & 0 & 0 & 1 & 0 & 1 \\
\hline & 0 & 0 & 0 & 0 & 1 & 0 & 0 & 0 & 0 & 1 & 0 & 1 \\
\hline F & 1 & 0 & 0 & 0 & 0 & 1 & 1 & 0 & 0 & 0 & 0 & 0 \\
\hline$G$ & 0 & 0 & 0 & 0 & 0 & 1 & 1 & 0 & 0 & 0 & 0 & 0 \\
\hline 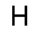 & 0 & 0 & 0 & 0 & 0 & 0 & 0 & 1 & 1 & 0 & 0 & 0 \\
\hline & 0 & 1 & 1 & 0 & 0 & 0 & 0 & 1 & 1 & 1 & 0 & 0 \\
\hline & 0 & 0 & 0 & 1 & 1 & 0 & 0 & 0 & 1 & 1 & 0 & 1 \\
\hline & 1 & 0 & 0 & 0 & 0 & 0 & 0 & 0 & 0 & 0 & 1 & 0 \\
\hline L & 0 & 0 & 0 & 1 & 1 & 0 & 0 & 0 & 0 & 1 & 0 & 1 \\
\hline
\end{tabular}

The matrix is normalized so that each alliance partner spends a proportional amount of trading with each of its peers. This is the matrix used for the exchange analysis (Table IV, below).

TABLE IV

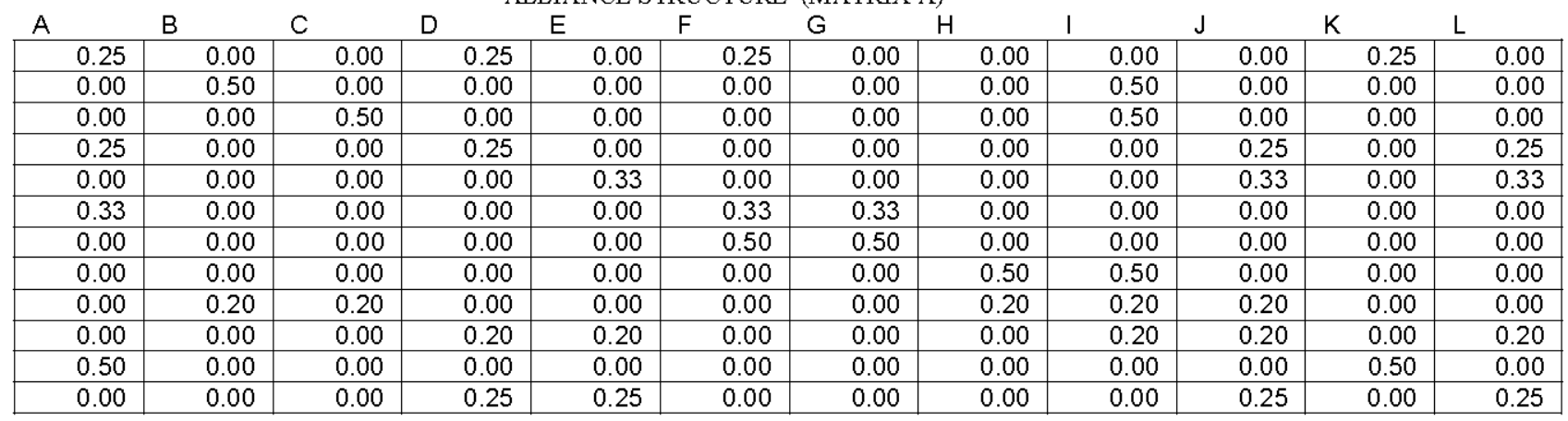


Calculations of stable exchange rates and actor resources proceeds as discussed previously in Appendix A. The resultant eigenvalue problem may be solved using the power method. Since all three of the matrices $(\mathrm{C}, \mathrm{X}, \mathrm{A})$ are interpretable as probabilities, the problem may be formulated as a Markov chain and then solved for an equilibrium vectors using a linear system of equations. This is the approach used herein. Rearranging the equations derived from the actor decision problem (equation 5a) we have the resultant linear system of equations, subject to the constraint that the stable probability vector must sum to 1 (equation $5 \mathrm{~b}$ ).

$\begin{array}{ll}\text { Eq. } 5 \mathrm{a} & \mathrm{R}=\mathrm{RZ} \\ \text { Eq. } 5 \mathrm{~b} & \mathrm{R}(\mathrm{l}-\mathrm{Z})=0 \\ & \sum \mathrm{R}=1\end{array}$

